Systematic Review

\title{
E Efficacy Assessment of Radiofrequency Ablation as a Palliative Pain Treatment in Patients with Painful Metastatic Spinal Lesions: A Systematic Review
}

Katharina Rosian, MSc, Katharina Hawlik, MD, and Brigitte Piso, MD

\footnotetext{
From: Ludwig Boltzmann Institute for Health Technology Assessment, Vienna, Austria

Address Correspondence: Katharina Rosian, MSc Ludwig Boltzmann Institute for Health Technology Assessment Garnisongasse 7/20 A-109o Vienna, Austria E-mail: katharina.rosian@hta.lbg. ac.at

Disclaimer: There was no external funding in the preparation of this manuscript. Conflict of interest: Each author certifies that he or she, or a member of his or her immediate family, has no commercial association

(i.e., consultancies, stock ownership, equity interest, patent/licensing arrangements, etc.) that might pose a conflict of interest in connection with the submitted manuscript.

Manuscript received: 12-20-2017

Revised manuscript received: 03-23-2018

Accepted for publication: 04-11-2018

Free full manuscript: www.painphysicianjournal.
} com
Background: Metastatic spinal lesions are difficult-to-treat entities that are most commonly associated with pain and severely reduced health-related quality of life (HRQoL). Within the last 5 to 10 years, radiofrequency ablation (RFA) has emerged as an option in the palliative treatment of vertebral metastases.

Objectives: Our review aims to evaluate the clinical effectiveness and safety of RFA, mostly in combination with vertebroplasty, in patients with painful vertebral metastases.

Study Design: The design of this study is a systematic review.

Methods: We conducted a systematic literature search and a manual search of 5 databases in December 2016. The review applied a methodological framework based on the HTA Core Mode ${ }^{\circledR}$. Data on each selected outcome category were synthesized according to the Grading of Recommendations, Assessment, Development and Evaluation (GRADE) scheme. Risk of bias was assessed using the Institute of Health Economics (IHE) Risk of Bias checklist for case series.

Results: We identified 299 citations. After applying the inclusion criteria, a total of 9 studies (4 prospective and 5 retrospective studies) were determined to be eligible. These studies included a total of 583 patients with vertebral metastases who were treated with RFA and, in most cases, received an additional vertebroplasty treatment $(n=437)$. The studies were categorized as having a moderate to high risk of bias. The strength of evidence was found to be "very low" for safety outcomes and could not be assessed for efficacy outcomes. Current evidence suggests that RFA leads to significant pain reduction. Furthermore, no major complications occurred when using RFA.

Limitations: A major concern is the low number of included patients and heterogeneity of study characteristics in most of the studies. The low number of patients also impeded comparison of the effectiveness of RFA alone to RFA in combination with vertebroplasty.

Conclusion: According to the available evidence, RFA may be safe and effective, especially for patients with painful vertebral metastases who show contraindications or unresponsiveness to conventional therapies (e.g., radiation) or for those who are at risk of tumor progression.

Key words: Radiofrequency ablation, vertebral metastases, metastatic spinal lesions, pain, clinical effectiveness, safety, palliative pain treatment

Pain Physician 2018: 21:E467-E476
D ony metastases are very difficult to treat and often unresponsive to conventional treatments (1). The vertebrae are most frequently affected by metastases, accounting for $40 \%$ of all bone metastatic lesions. At the time of death, about $80 \%$ of cancer patients are affected by bone metastases, and of those, about $50 \%$ are affected by vertebral metastases (2-4).

Over the last 2 decades, there has been substantial progress in the symptomatic treatment of unresect- 
able tumors and metastases in the area of the spine. Treatment options include cytoreductive therapies, i.e., radiation, hormonal ablation, and chemotherapy; and treatments that do not directly attack the tumor cells, but inhibit osteoclast activity $(4,5)$. In some patients, however, none of these treatment options provide sufficient symptom control.

In the last 5 to 10 years, radiofrequency ablation (RFA) has emerged as a feasible option in the palliative treatment of vertebral metastases because of short procedure times, its minimal invasiveness, and its capacity to be performed on an ambulatory basis $(5,6)$. RFA was first described in 1992 as an auspicious technique for the treatment of osteoid osteomas by Rosenthal et al (7-9). At present, RFA is used as an image-guided, minimally invasive thermal ablation procedure for solid tumors $(10,11)$. A metastasis adjacent to neurological structures, however, can present a contraindication with RFA due to the risk of neurological injury and secondary fractures of large lesions in the vertebrae (12).

The present systematic review aimed to evaluate the clinical effectiveness and safety of RFA with and without vertebroplasty in comparison to the standard of care (e.g., radiotherapy) for patients with painful vertebral metastases for whom a curative tumor treatment was not indicated or symptomatic improvement did not occur even after reaching a maximal radiation dose; outcomes included pain, functional status, healthrelated quality of life (HRQoL), and complications.

\section{Methods}

This systematic review was conducted in accordance with the Preferred Reporting Items for Systematic Reviews and Meta-Analyses (PRISMA) statement (13). The systematic review is based on 4 domains of the HTA (Health Technology Assessment) Core Model ${ }^{\circledR}$ developed within the European Network for Health Technology Assessment (EUnetHTA); these domains include 1) health problem and current use of technology (CUR), 2) description and technical characteristics of technology (TEC), 3) safety (SAF), and 4) clinical effectiveness (EFF) (14).

\section{Literature Searches}

We performed a systematic literature search in the following databases: Ovid MEDLINE, Embase, the Cochrane Library, CRD (DARE, NHS-EED, HTA), and PubMed (Appendix 1). Our systematic search was not limited to a specific study design or time period (from the earliest records to December 2016). The systematic literature search was completed by a manual search for additional records, using the keywords "radiofrequency," "ablation," "spine," and "metastases." Abstracts were screened by 2 independent researchers.

\section{Eligibility Criteria}

Inclusion criteria for relevant studies were as follows: 1) patients with solitary fracture-related vertebral metastases of all entities, for whom a curative tumor treatment (vertebral body extension and stabilization) was not indicated, or for whom symptomatic improvement did not occur given maximal radiation dose or radiation-resistant lesions; 2) RFA with or without vertebroplasty or other add-on therapies (e.g., radiation); 3) randomized controlled trials (RCTs), nonrandomized controlled trials (NRS), prospective and retrospective case series; 4) sample $>30$ patients in retrospective studies; 5) published in English or German; 6) sub-analytical results were excluded if already published by the same investigator in a previous article.

\section{Data Extraction}

Two reviewers independently extracted data from eligible studies for inclusion in predefined tables. The extraction table summarizes the following characteristics: study design, demographic characteristics, intervention, sponsoring, setting, mean duration of intervention, follow-up period, total vertebral treated metastatic bodies/lesions, efficacy outcomes (increased pain, functional status, health-related quality of life (HRQoL), satisfaction with treatment, recurrence of vertebral metastases, mortality), as well as safety outcomes (major complications, procedure-related adverse events, and non-procedure-related adverse events).

\section{Methodological Quality Assessment}

Data on each selected outcome category were synthesized across studies according to the GRADE (Grading of Recommendations, Assessment, Development and Evaluation) scheme (15). Each study was rated by two independent researchers. A third researcher was called to resolve differences in case of disagreement. The GRADE scheme uses 4 categories to rank the strength of evidence of included studies (Table 1). A more detailed list of applied criteria can be found in the recommendations of the GRADE Working Group (15).

No further data processing (e.g., indirect comparison) was conducted. The studies were systematically assessed for quality and risk of bias by 2 independent researchers using the Institute of Health Economics 
(IHE) Risk of Bias checklist for case series (16) (Fig. 1). A third researcher was called to resolve differences in case of disagreement. We extended the checklist for an overall rating that measured risk of bias, ranging from low to moderate to high, to enable comparison of the studies with each other (Table 2 ).

\section{Results}

\section{Study Selection}

In total, 299 citations were identified through the systematic search. After abstract screening, 58 full texts were assessed for eligibility. A total of 9 articles, 4 prospective single-arm and 5 retrospective single-arm studies, partly multicenter, were included (Fig. 2) (4-7, 17-21). Five studies with subgroup analyses (22-26) were additionally included to compare findings and patient characteristics. However, since they presented sub-analyses of results of already included papers $(4,5,18,21)$, we excluded them from the final analyses.

\section{Study Characteristics}

A total of 604 patients (293 women, 219 men, 92 not specified) were enrolled in the included studies, of which 583 patients had vertebral metastases. These patients suffered from severe pain and were unresponsive to previous treatments (e.g., analgesics, radiation, or chemotherapy). The mean age ranged from 61.0 to 69.6 years across studies. One study did not report baseline characteristics for age and gender (4). The mean follow-up periods differed considerably, with a range of 24-48 hours to 60 months of post-treatment follow-up.

A variety of ablation systems were used in the studies; the most commonly used were the STAR ${ }^{\circledR}$ Tumor Ablation System (DFine Inc., San Jose, CA) and the CAVITY SpineWand ${ }^{\circledR}$ (ArthroCare Corporation, Austin, TX). The majority of patients $(437 ; 72.4 \%)$ received additional vertebroplasty treatment following RFA. One study did not report the number of patients who received vertebroplasty, but did report that vertebroplas-

Table 1. GRADE categories to rank the strength of evidence (15).

\begin{tabular}{|l|l|}
\hline High & $\begin{array}{l}\text { We are very confident that the true effect lies close to } \\
\text { that of the estimate of the effect }\end{array}$ \\
\hline Moderate & $\begin{array}{l}\text { We are moderately confident in the effect estimate: } \\
\text { the true effect is likely to be close to the estimate } \\
\text { of the effect, but there is a possibility that it is } \\
\text { substantially different }\end{array}$ \\
\hline Low & $\begin{array}{l}\text { Our confidence in the effect estimate is limited: the } \\
\text { true effect may be substantially different from the } \\
\text { estimate of the effect }\end{array}$ \\
\hline Very Low & $\begin{array}{l}\text { Evidence is either unavailable or does not permit a } \\
\text { conclusion }\end{array}$ \\
\hline
\end{tabular}

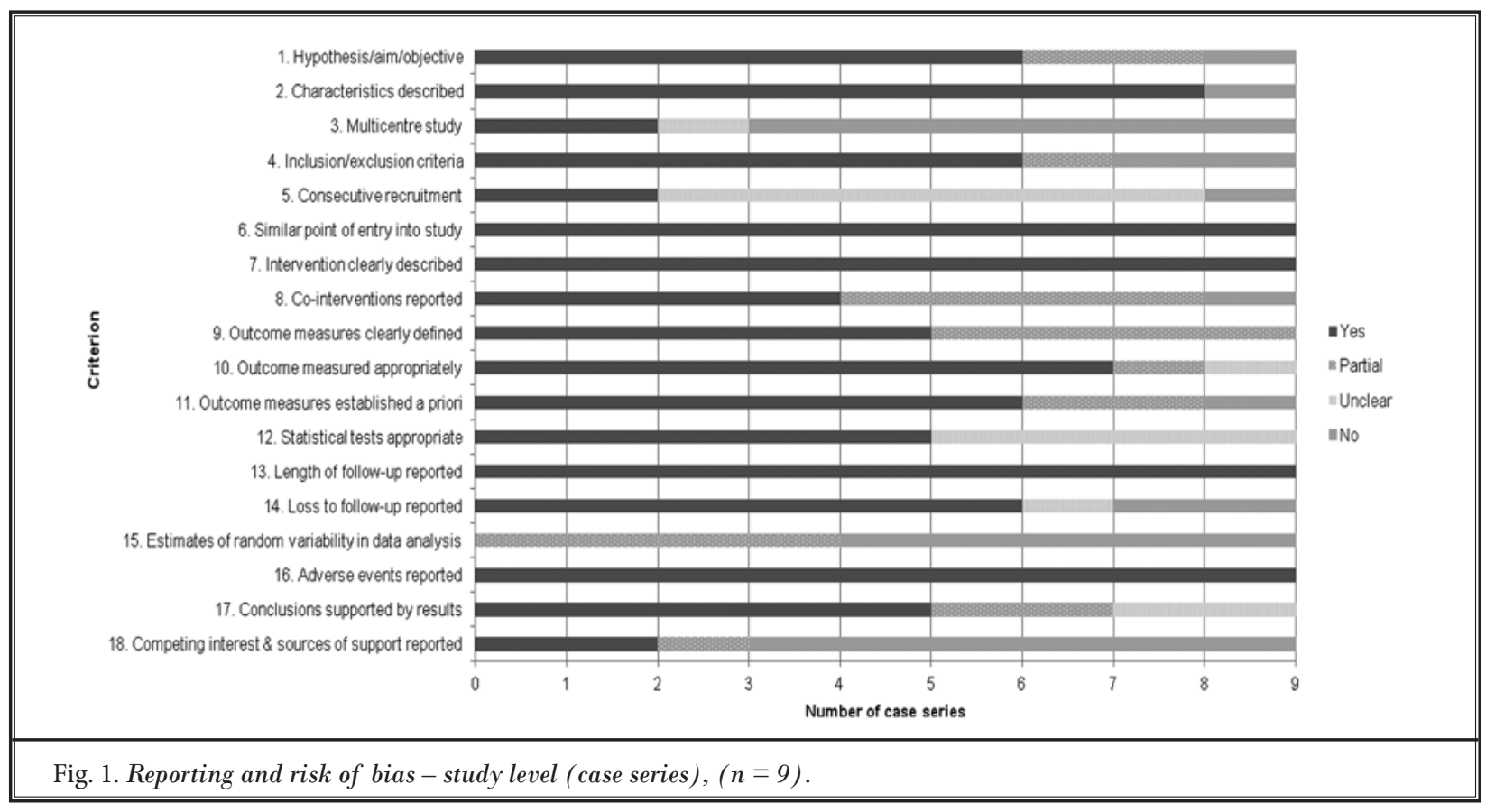


Pain Physician: September/October 2018: 21:E467-E476

\begin{tabular}{|c|c|c|c|c|c|c|c|}
\hline 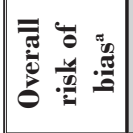 & 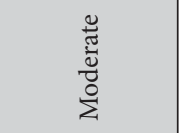 & 点 & 点 & 点 & 点 & 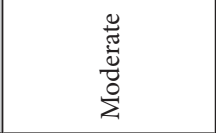 & 袁 \\
\hline 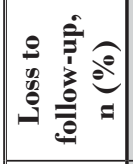 & 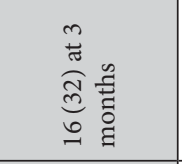 & ન્ & $\underset{\infty}{\Xi}$ & 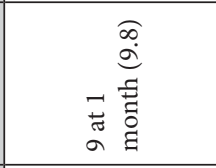 & $\tilde{z}$ & $\begin{array}{l}\stackrel{f}{d} \\
\text { d }\end{array}$ & 。 \\
\hline 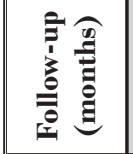 & $m$ & 8 & - & 6 & $\tilde{z}$ & 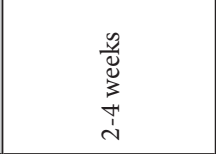 & 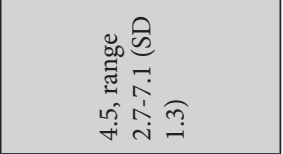 \\
\hline 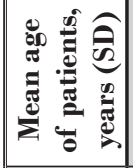 & 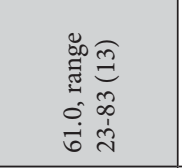 & 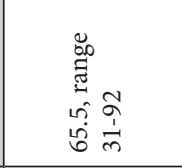 & 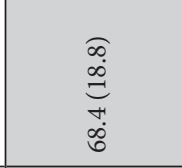 & 艺 & 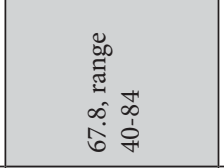 & 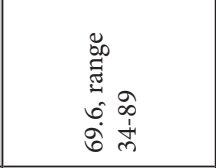 & 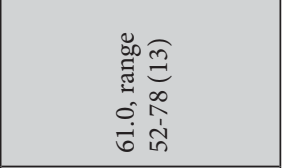 \\
\hline 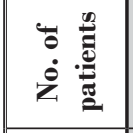 & in & $\stackrel{\circ}{i}$ & N & $\alpha$ & i & m & $\stackrel{-}{-}$ \\
\hline$\frac{0}{3}$ & 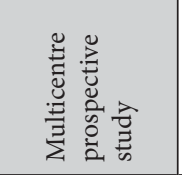 & 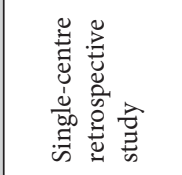 & 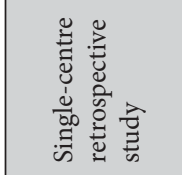 & 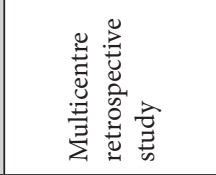 & 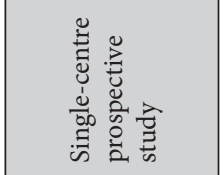 & 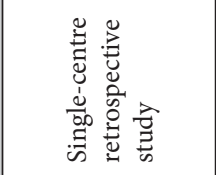 & 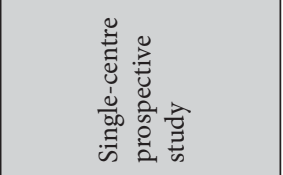 \\
\hline 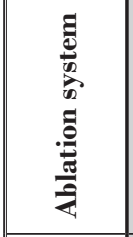 & 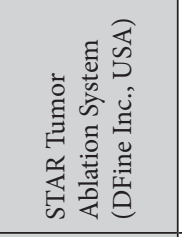 & 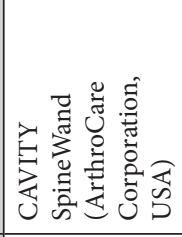 & 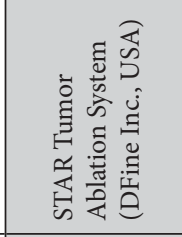 & 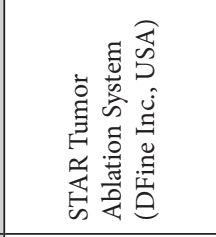 & 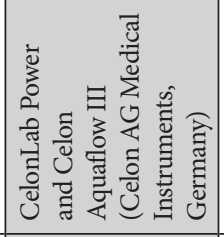 & 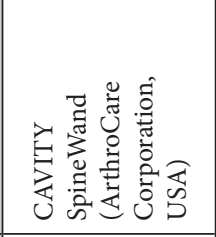 & 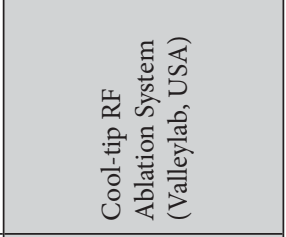 \\
\hline 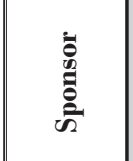 & 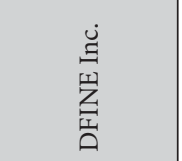 & 号 & 号 & 号 & 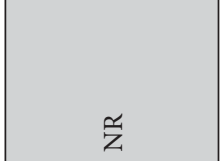 & 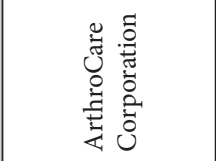 & 号 \\
\hline है & 岕 & 姶 & 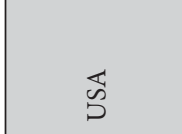 & 峁 & 衰 & 㟔 & $\begin{array}{l}\text { : } \\
\text { 心్ } \\
\text { 心్}\end{array}$ \\
\hline$\stackrel{\varrho}{\Xi}$ & 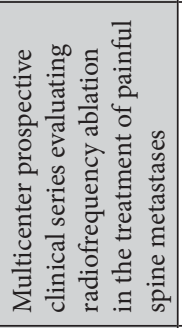 & 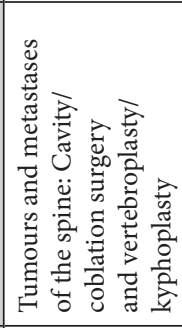 & 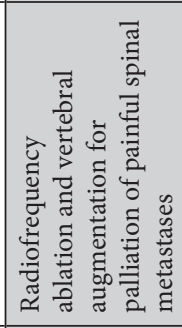 & 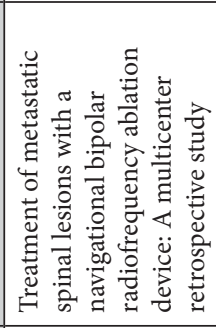 & 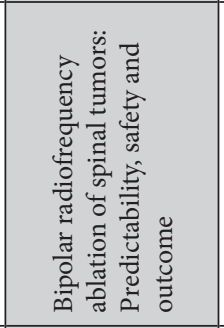 & 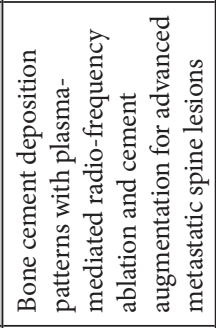 & 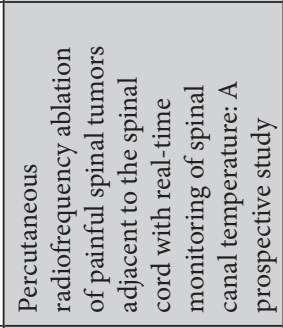 \\
\hline 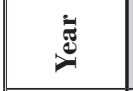 & $\stackrel{\circ}{\stackrel{0}{~}}$ & $\stackrel{\text { na }}{\stackrel{i}{i}}$ & $\stackrel{n}{\stackrel{i}{*}}$ & $\stackrel{\vec{d}}{\stackrel{i}{n}}$ & $\underset{\sim}{\vec{i}}$ & ذे & ઠิે \\
\hline 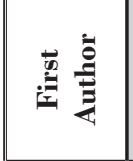 & $\begin{array}{l}\frac{\pi}{00} \\
\cong\end{array}$ & 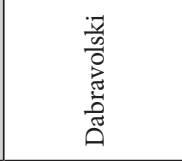 & $\frac{\mathscr{\tilde { J }}}{\tilde{\Xi}}$ & $\begin{array}{l}\frac{\pi}{\pi} \\
\frac{\pi}{5} \\
\frac{3}{4}\end{array}$ & $\begin{array}{l}\mathscr{A} \\
\text { J }\end{array}$ & 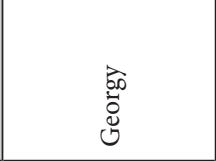 & 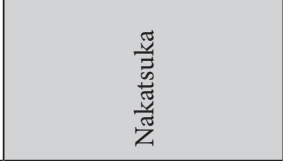 \\
\hline$\dot{\vec{\varpi}}$ & e & $\sqrt{6}$ & હ્d & I & $\stackrel{\varrho}{=}$ & $\Xi$ & 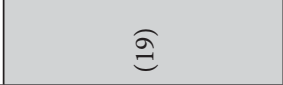 \\
\hline
\end{tabular}




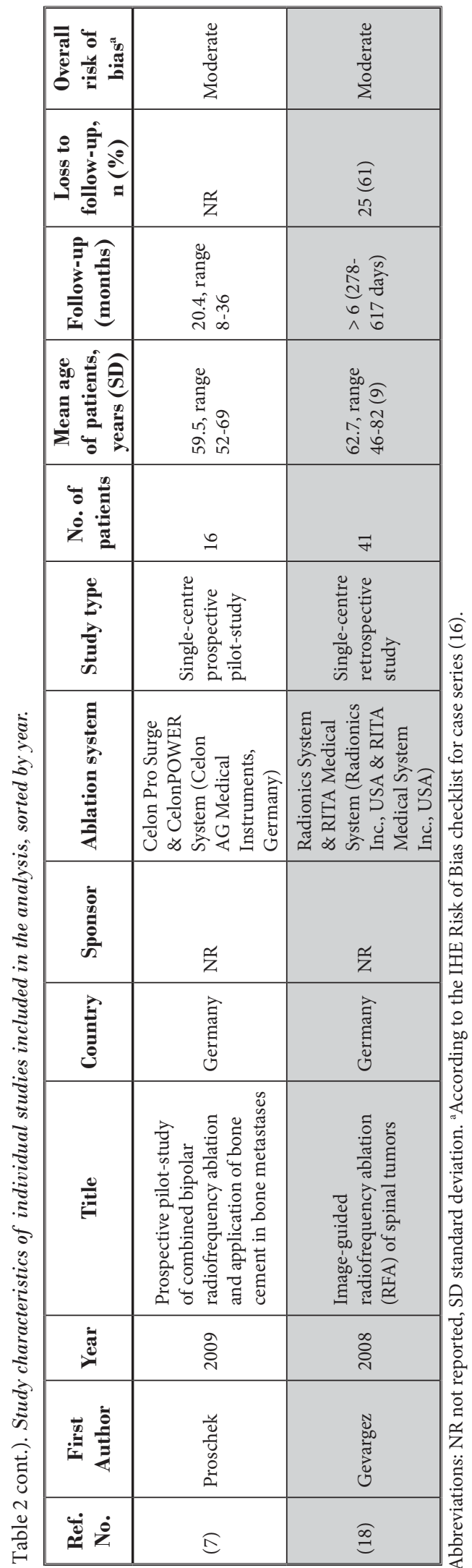

ty treatment was performed in $95 \%(n=110)$ of total ablation procedures (21). Loss to follow-up ranged from 0 to $61 \%$. One study reported a particularly high loss to follow-up rate, which the researchers attributed to a long follow-up period ranging from 278-617 days and a more severe progression of the primary cancer at study entry (19). Study characteristics reported by each paper are summarized in Table 2 .

\section{Quality of Evidence}

Risk of bias was assessed for the 9 studies according to the IHE checklist (16); the overall risk of bias is presented in Table 2. None of the studies were categorized with a low risk of bias; 4 studies showed a moderate risk of bias; and 5 studies showed a high risk of bias due to unclear reporting of statistical analyses, no reporting of estimates of random variability in relevant outcome data, unclear consecutive recruitment of patients, and no statement of competing interests and sources of support. The ratings for each individual criterion are plotted in Fig. 1.

Overall, the strength of evidence for clinical effectiveness according to GRADE could not be assessed due to the lack of trials with a comparative treatment arm. For safety outcomes, the strength of evidence was determined to be "very low," due mainly to missing data for control groups and overlapping samples of patients in 2 studies (Table 3 ).

\section{Effectiveness of RFA}

No comparative studies assessing the clinical effectiveness and safety outcomes of RFA for metastatic spinal lesions could be identified. Nevertheless, 4 prospective studies of the clinical effectiveness of RFA examined pain reduction outcomes $(6,7,17,20)$. Three of these studies specified the instruments used to assess pain reduction (Visual Analog Scale and Numeric Pain Rating Scale); these 3 studies reported significant pain relief after treatment with RFA $(6,7,20)$. The fourth study only stated the proportion of patients $(52.8 \%)$ who reported post-interventional pain reduction and did not specify the pain measure used (17).

Bagla et al (6) reported a statistically significant decrease in pain at 1 and 3 months (a decrease of 3.3 and 3.8 points, respectively; $P<0.0001)$ relative to baseline. Similar results were reported by Nakatsuka et al (20), who found a decrease in pain of 4.8 points after one week $(P<0.00005)$; 9 out of 10 patients in that study experienced sustained pain relief until the moment of death (20). Proschek et al (7) also described a decrease in pain directly after treatment with RFA (decrease of 2.4, $P<0.018$ ) or RFA in combination with vertebroplasty (decrease of 2.6, $P<0.005$ ). Furthermore, they showed that pain levels continued to decline 15-36 months after baseline for both RFA and RFA with vertebroplasty (decrease of 3.9, $P$ $<0.008$ and decrease of $4.1, P<0.005$, respectively). 


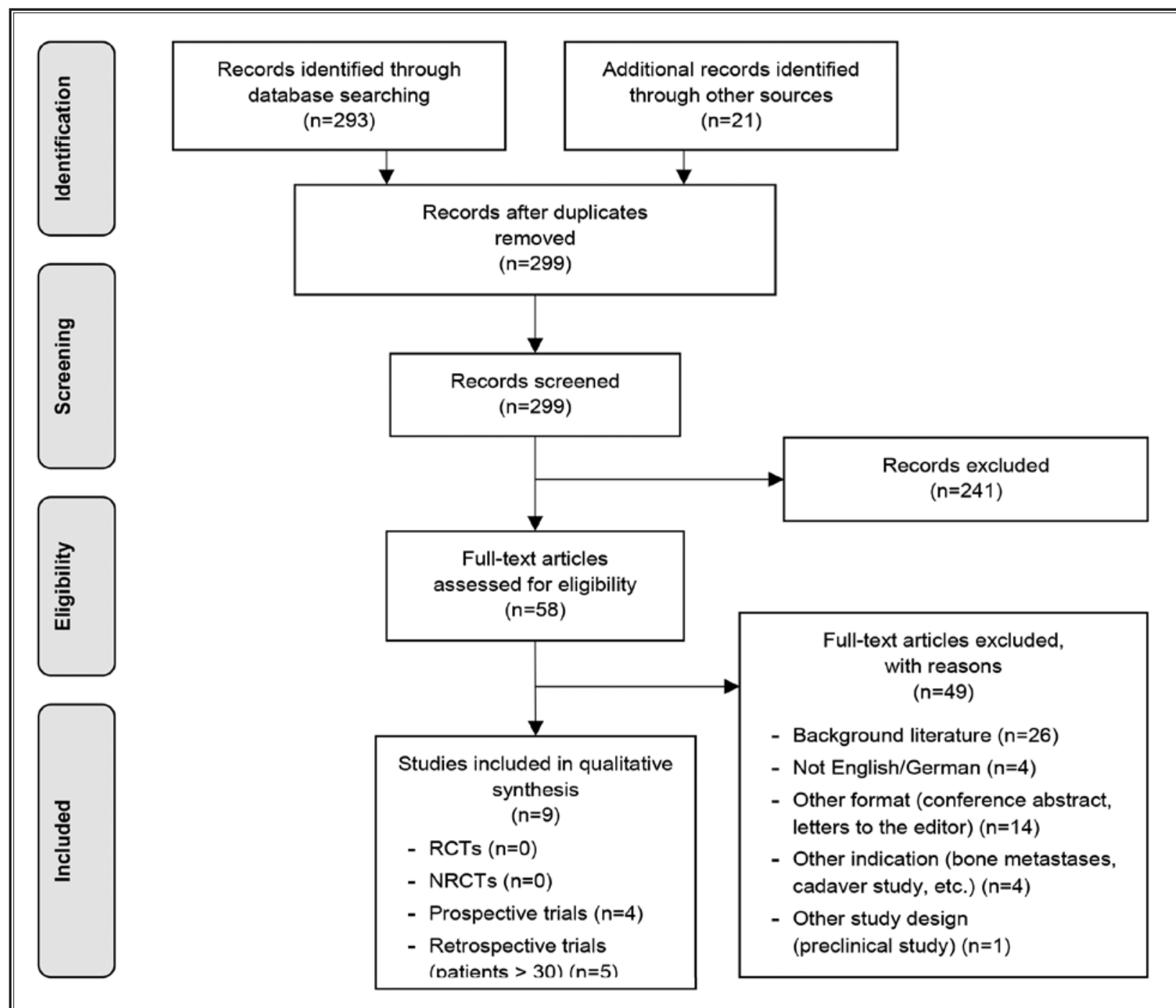

Fig. 2. PRISMA flow diagram outlining selection process for included studies.

Outcomes for the progression or recurrence of vertebral metastases were only observed in one prospective study, in which none of the patients had a local relapse after treatment with RFA or RFA in combination with vertebroplasty (7).

HRQoL was assessed by 2 studies using different measures: Bagla et al (6) applied the Functional Assessment of Cancer Therapy-General 7 (FACT-G7) and the Functional Assessment of Cancer Therapy Quality-ofLife Measurement in Patients with Bone Pain (FACT-BP) (6); the other study, Proschek at al (7) used the Oswestry Disability Questionnaire. Bagla et al (6) reported statistically significant improvements throughout 1 month and
3 months of treatment, with a FACT-G7 improvement of 4.8 and 5.2, respectively, and a FACT-BP improvement of 14.7 and 16.3 , respectively, compared to baseline. Backrelated disability was also assessed, with patients showing statistically significant improvements from baseline $(52.9 \%)$ to 1 month (40\%) to 3 months (37\%); these changes represent an improvement in functional status from severe to moderate disability (Modified Oswestry Disability Index) (6). Using the Oswestry Disability Questionnaire, Proschek et al (7) observed significant improvements of $30 \%$ after 3-6 months for patients treated with RFA and after 15-36 months for patients treated with RFA and vertebroplasty, compared to 
Table 3. Evidence profile: Efficacy and safety of radiofrequency ablation for metastatic spinal lesions (GRADE).

\begin{tabular}{|c|c|c|c|c|c|c|c|}
\hline $\begin{array}{c}\text { No. of } \\
\text { Studies/ Pts }\end{array}$ & Study Design & $\begin{array}{c}\text { Estimate of } \\
\text { Effect }\end{array}$ & $\begin{array}{c}\text { Study } \\
\text { Limitations }\end{array}$ & Inconsistency & Indirectness & $\begin{array}{c}\text { Other } \\
\text { Modifying } \\
\text { Factors } \\
\end{array}$ & $\begin{array}{c}\text { Strength of } \\
\text { Evidence }\end{array}$ \\
\hline \multicolumn{8}{|l|}{ Efficacy $^{\mathrm{a}}$} \\
\hline \multicolumn{8}{|l|}{ Safety } \\
\hline \multicolumn{8}{|c|}{ Overall complications } \\
\hline $4 / 112$ & $\begin{array}{l}\text { Prospective } \\
\text { single arm } \\
\text { studies }\end{array}$ & $\begin{array}{c}20 / 112 \\
\text { (17.9\%); Range: } \\
19.4-40 \%\end{array}$ & $\begin{array}{c}\text { Serious } \\
\text { limitations }(-1)^{\mathrm{b}}\end{array}$ & 0 & Direct & $\begin{array}{l}\text { Imprecise data } \\
(-1)^{c}\end{array}$ & Very low \\
\hline $5 / 471^{d}$ & $\begin{array}{l}\text { Retrospective } \\
\text { single arm } \\
\text { studies }\end{array}$ & $\begin{array}{c}58 / 471 \\
(12.3 \%) ; \text { Range: } \\
4.3-21.9 \%\end{array}$ & $\begin{array}{l}\text { Serious } \\
\text { limitations }(-1)^{\mathrm{b}}\end{array}$ & 0 & Direct & $\begin{array}{c}\text { Imprecise data } \\
(-1)^{\mathrm{e}}\end{array}$ & Very low \\
\hline \multicolumn{8}{|c|}{ Major complications (procedure-related) * } \\
\hline $4 / 112$ & $\begin{array}{l}\text { Prospective } \\
\text { single arm } \\
\text { studies }\end{array}$ & 0 & $\begin{array}{c}\text { Serious } \\
\text { limitations }(-1)^{\mathrm{b}}\end{array}$ & 0 & Direct & $\begin{array}{l}\text { Imprecise data } \\
(-1)^{c}\end{array}$ & Very low \\
\hline $5 / 471^{d}$ & $\begin{array}{l}\text { Retrospective } \\
\text { single arm } \\
\text { studies }\end{array}$ & 0 & $\begin{array}{c}\text { Serious } \\
\text { limitations }(-1)^{\mathrm{b}}\end{array}$ & 0 & Direct & $\begin{array}{l}\text { Imprecise data } \\
(-1)^{\mathrm{e}}\end{array}$ & Very low \\
\hline \multicolumn{8}{|c|}{ Adverse events (procedure-related) } \\
\hline $4 / 112$ & $\begin{array}{l}\text { Prospective } \\
\text { single arm } \\
\text { studies }\end{array}$ & $\begin{array}{c}\text { 5/112 }(4.5 \%) ; \\
\text { Range: } \\
10-11.1 \% \\
\end{array}$ & $\begin{array}{c}\text { Serious } \\
\text { limitations }(-1)^{\mathrm{b}}\end{array}$ & 0 & Direct & $\begin{array}{l}\text { Imprecise data } \\
(-1)^{c}\end{array}$ & Very low \\
\hline $5 / 471^{d}$ & $\begin{array}{l}\text { Retrospective } \\
\text { single arm } \\
\text { studies }\end{array}$ & $\begin{array}{l}11 / 471 \text { (2.3\%); } \\
\text { Range: } 0-9.8 \%\end{array}$ & $\begin{array}{c}\text { Serious } \\
\text { limitations }(-1)^{\mathrm{b}}\end{array}$ & 0 & Direct & $\begin{array}{c}\text { Imprecise data } \\
(-1)^{\mathrm{e}}\end{array}$ & Very low \\
\hline \multicolumn{8}{|c|}{ Adverse events (not procedure-related) } \\
\hline $4 / 112$ & $\begin{array}{l}\text { Prospective } \\
\text { single arm } \\
\text { studies }\end{array}$ & $\begin{array}{l}\text { 15/112 (13.4\%); } \\
\text { Range: } 8.3-30 \%\end{array}$ & $\begin{array}{c}\text { Serious } \\
\text { limitations }(-1)^{\mathrm{b}}\end{array}$ & 0 & Direct & $\begin{array}{l}\text { Imprecise data } \\
(-1)^{c}\end{array}$ & Very low \\
\hline $5 / 471^{\mathrm{d}}$ & $\begin{array}{l}\text { Retrospective } \\
\text { single arm } \\
\text { studies }\end{array}$ & $\begin{array}{l}\text { 74/471 (15.7\%); } \\
\text { Range: } 4.3-73 \%\end{array}$ & $\begin{array}{c}\text { Serious } \\
\text { limitations }(-1)^{\mathrm{b}}\end{array}$ & 0 & Direct & $\begin{array}{c}\text { Imprecise data } \\
(-1)^{\mathrm{e}}\end{array}$ & Very low \\
\hline
\end{tabular}

Nomenclature for GRADE table:

Limitations: 0: no limitations or no serious limitations; -1: serious limitations

Inconsistency: NA: Not applicable (only one trial); 0: no important inconsistency; -1: important inconsistency

Indirectness: 0 : direct, no uncertainty, -1 : some uncertainty, -2 : major uncertainty

Other modifying factors: publication bias likely $(-1)$, imprecise data $(-1)$, strong or very strong association $(+1$ or +2$)$, dose-response gradient $(+1)$, plausible confounding $(+1)$

${ }^{*}$ None of the included studies reported any serious adverse events related to the procedure.

${ }^{a}$ Due to the lack of a controlled group, no data on efficacy outcomes can be compared and synthesized.

${ }^{b}$ No control group.

'Small numbers of patients in included studies.

d72 patients of (21) may already be included in another retrospective study (4).

${ }^{\mathrm{e}}$ Overlap of patients in 2 studies.

baseline. In summary, these 2 studies suggest that RFA leads to significant pain reduction as well as improvement in HRQoL.

Since the treatment with RFA for vertebral metastases is palliative and does not aim to prolong life, mortality outcomes were reported in only 2 studies, and ranged from 5 to 10 deaths during each study's followup period of 3 and 4.5 months, respectively $(6,20)$.

\section{Safety of RFA}

In terms of safety, all of the 9 included studies reported complications; however, no major complications 
occurred in any of the studies. The overall complication rates were similar across all but 2 studies $(18,20)$. Higher complication rates in these 2 studies might be related to different follow-up periods (2-4 weeks vs. 4.5 months) and the stage of the disease.

Overall, out of the 583 patients with vertebral metastases included across all 9 studies, adverse events (procedure-related or non-procedure-related) occurred in 105 patients $(18.0 \%)$ who completed follow-up. Occurrence of adverse events related to RFA ranged from $5.6 \%$ to $11.1 \%$ of the patients in each study. Increased pain and numbness $(6 / 583)(17,19)$, and post-procedure radicular symptoms and pain $(5 / 583)(18,21)$ were the most frequently described procedure-related adverse events. Procedure-related adverse events were not reported in 4 of the included studies (4-7).

Rates of adverse events that were not RFA-related (but vertebroplasty-related) ranged from $4.3 \%$ to 73.0\%. Thereby, cement extravasation after vertebroplasty was the most frequently reported, occurring in $15.3 \%$ of patients $(67 / 437)(4,5,18)$. One study did not report any RFA-unrelated adverse events (21).

\section{Discussion}

Vertebral metastases are difficult-to-treat entities that most frequently affect patients who are suffering from breast, lung, or prostate cancer. Most commonly, these metastases are associated with progressive pain and severely reduced HRQoL. Furthermore, untreated or progressing spinal metastases can lead to pathological fractures and spinal instability, hypercalcemia, or spinal cord compression $(5,6,27)$.

Individual studies have used differing RFA systems and interventions, warranting a comparison. For instance, the RFA systems applied in the studies included in this review differed with respect to the temperature used for ablation: the STAR ${ }^{\circledR}$ Tumor Ablation System (DFine Inc., San Jose, CA) uses up to $50^{\circ} \mathrm{C}$, whereas the CAVITY-SpineWand ${ }^{\circledR}$ (ArthroCare Corporation, Austin, TX) only uses cold energy at $42^{\circ} \mathrm{C}$. Studies also differed with respect to ablation method: the STAR ${ }^{\circledR}$ Tumor Ablation System has a bipolar extensible radiofrequency electrode at the top of the articulated distal segment. The segment can be curved up to $90^{\circ}$ and is therefore able to access multiple areas of the tumor. This system also comprises a combination of 2 thermocouples, which enable real-time temperature monitoring $(2,34)$. In contrast, the CAVITY-SpineWand ${ }^{\circledR}$ probe creates a cave in the tumor tissue by plasma generation (coblation-controlled ablation) at a low temperature on the basis of plasma-mediated high-frequency energy. Coblation (radiofrequency-based plasma ablation) refers to a controlled ablation with a pre-bent plasma probe. The probe can be rotated so that the ablation can take place in several directions. Coblation can be combined with additional procedures, in particular with vertebroplasty $(5,22,23)$. Finally, patients across these studies differed with regard to their histories of treatment with additional therapies, such as radiation therapy or analgesics, before or following RFA.

It is possible that these therapies and the different RFA systems have had a confounding effect on the outcomes of the studies (such as pain and HRQoL). Further, it should be recognized that most of the effectiveness outcomes were patient-reported and hence subject to a high risk of bias.

A major concern of most of the identified prospective studies was the low number of included patients; one study, for instance, only included 10 patients (20). In order to identify rare complications, low patient numbers are insufficient. Furthermore, the inclusion criteria were slightly different among studies, with different entry points. To determine the best time for the initiation of treatment studies, including more patients and having similar entry points would be useful.

Moreover, the follow-up period varied substantially between studies, ranging from 24-48 hours to 60 months post-treatment, including 2 studies that had a very short follow-up period of $2-4$ weeks $(18,21)$ and one study that observed its patients only 24-48 hours post-treatment (17). Reliable data on long-term safety and efficacy outcomes are missing. However, long-term follow-up is challenging for patients with metastatic spinal lesions due to high morbidity and mortality rates - making data collection extremely difficult. The question of meaningful long-term follow-up periods for terminal patients is an important consideration.

For 2 of the included retrospective studies, it can be assumed - though it is not clearly stated - that the observed patient populations overlap, since some of the 72 patients included in Wallace et al seem to be included among the 92 patients of Anchala et al $(4,21)$. The outcomes of these studies were reported separately, but data may be imprecise as a result.

RFA for vertebral metastases is associated with low numbers of complications and does not require the interruption of adjuvant therapies (e.g., radiation or chemotherapy) $(5,21)$. Due to the advancing nature of the disease, however, an associated vertebroplasty in addi- 
tion to RFA is common. A recently published Guideline on Percutaneous Vertebral Augmentation recommends treatment with vertebroplasty following different tumor treatments (like RFA) in patients with painful vertebrae due to metastases in order to achieve pain relief and the consolidation of vertebra (30). Hence, while additional vertebroplasty may be indicated following RFA $(18,28,29)$, it can limit the ability to adequately assess the efficacy of RFA; vertebroplasty may also be a confounder of the post-interventional pain evaluation. In all of the studies included for this review, vertebroplasty was performed if there was a risk of fracture and instability of the bone structure due to tumor removal. Therefore, an evaluation of the effect of RFA alone in comparison to RFA in combination with vertebroplasty was not feasible due to the low number of cases in the studies. A comparative study design or larger numbers of patients will be required to compare the effect of RFA in combination with vertebroplasty and RFA alone for the treatment of painful vertebral metastases.

The present systematic review indicated that there is presently only limited evidence for the clinical effectiveness and safety of RFA treatment for vertebral metastases. Furthermore, systematic reviews that analyzed RFA for lung tumors, malignant biliary obstruction, or small renal neoplasms have also shown that the level of evidence is low, with no RCTs comparing the use of RFA with other treatment options. Nevertheless, RFA may also be a safe and effective treatment option for lung tumors, malignant biliary obstruction, and small renal neoplasms (31-33).
Despite the heterogeneity of study characteristics, the included case series show that image-guided RFA with or without vertebroplasty might be a feasible and safe technique for patients with painful metastatic spinal lesions - particularly since no serious complications were reported. Hence, major complications may be rare and may only be determined in studies with larger patient samples. Registry acquisition also provides a sound basis to record potential and rare adverse events $(4,29,34)$. Importantly, the natural course of metastatic spinal lesions is fatal with intolerable pain. Every therapy providing pain relief and causing no major complications may thus be justified on ethical grounds (12).

\section{Conclusion}

In patients with vertebral metastases who are unresponsive or have contraindications for conventional treatments such as radiation or chemotherapy, RFA is a safe therapy that can be effective to palliate pain. However, there is a substantial lack of evidence to evaluate the applicability of RFA. Further studies should be conducted to help determine the exact patient group that would benefit most from the intervention and to compare individual operation techniques (e.g., differences in RFA techniques, vertebroplasty following RFA, etc.). Study registries may serve this purpose well. Further evaluations of RFA (in combination with vertebroplasty) for longer-term clinical efficacy and complication rates - in particular evaluations comparing RFA with traditional therapies, e.g., radiation - are desirable.

\section{References}

1. Pusceddu C, Sotgia B, Fele RM, Ballicu $\mathrm{N}$, Melis L. Combined microwave ablation and cementoplasty in patients with painful bone metastases at high risk of fracture. Cardiovasc Intervent Radiol 2016; 39:74-80.

2. Ma Y, Wallace AN, Madaelil TP, Jennings JW. Treatment of osseous metastases using the Spinal Tumor Ablation with Radiofrequency (STAR) system. Expert Rev Med Devices 2016; 13:1137-1145.

3. Goetz MP, Callstrom MR, Charboneau JW, Farrell MA, Maus TP, Welch TJ, Wong GY, Sloan JA, Novotny PJ, Petersen IA, Beres RA, Regge D, Capanna
R, Saker MB, Grönemeyer DH, Gevargez A, Ahrar K, Choti MA, de Baere TJ, Rubin J. Percutaneous image-guided radiofrequency ablation of painful metastases involving bone: A multicenter study. J Clin Oncol 2004; 22:300-306.

4. Anchala PR, Irving WD, Hillen TJ, Friedman MV, Georgy BA, Coldwell DM, Tran ND, Vrionis FD, Brook A, Jennings JW. Treatment of metastatic spinal lesions with a navigational bipolar radiofrequency ablation device: A multicenter retrospective study. Pain Physician 2014; 17:317-327.

5. Dabravolski D, Lahm A, Eser J, Merk H.
Tumours and metastases of the spine: Cavity/coblation surgery and vertebroplasty/kyphoplasty. Orthopade 2015; 44:806-819.

6. Bagla S, Sayed D, Smirniotopoulos J, Brower J, Neal Rutledge J, Dick B, Carlisle J, Lekht I, Georgy B. Multicenter prospective clinical series evaluating radiofrequency ablation in the treatment of painful spine metastases. Cardiovasc Intervent Radiol 2016; 39:1289-1297.

7. Proschek D, Kurth A, Proschek P, Vogl TJ, Mack MG. Prospective pilot-study of combined bipolar radiofrequency ablation and application of bone cement in 
bone metastases. Anticancer Res 2009; 29:2787-2792.

8. Lane MD, Le HBQ, Lee $S$, Young C, Heran MKS, Badii M, Clarkson PW, Munk PL. Combination radiofrequency ablation and cementoplasty for palliative treatment of painful neoplastic bone metastasis: Experience with 53 treated lesions in 36 patients. Skeletal Radiol 2011; 40:25-32.

9. Rosenthal D, Hornicek FJ, Wolfe MW, Jennings C, Gebhardt MC, Mankin HJ. Percutaneous radiofrequency coagulation of osteoid osteoma compared with operative treatment. J Bone Joint Surg Am 1998; 80:815-821.

10. Dupuy DE, Liu D, Hartfeil D, Hanna L, Blume JD, Ahrar K, Lopez R, Safran $H$, DiPetrillo T. Percutaneous radiofrequency ablation of painful osseous metastases: A multicenter American College of Radiology imaging network trial. Cancer 2010; 116:989-997.

11. Sutcliffe $P$, Connock M, Shyangdan D, Court R, Kandala N-B, Clarke A. A systematic review of evidence on malignant spinal metastases: Natural history and technologies for identifying patients at high risk of vertebral fracture and spinal cord compression. Health Technol Assess 2013; 17:1-274.

12. Mavrogenis AF, Angelini A, Vottis C, Pala E, Calabro T, Papagelopoulos PJ, Ruggieri P. Modern palliative treatments for metastatic bone disease: Awareness of advantages, disadvantages, and guidance. Clin J Pain 2016; 32:337-350.

13. Moher D, Liberati A, Tetzlaff J, Altman DG; The PRISMA Group. Preferred reporting items for systematic reviews and meta-analyses: The PRISMA statement. PLoS Med 2009; 6:e1000097.

14. EUnetHTA Joint Action 2 Work Package 8. HTA Core Model ${ }^{\circledR}$ Version 3.0 (Pdf). Helsinki, Finland: European Network for Health Technology Assessment (EUnetHTA); 2016. www.htacoremodel. info/BrowseModel.aspx. Date accessed: 04/01/2017.

15. Guyatt G, Oxman AD, Akl EA, Kunz R, Vist G, Brozek J, Norris S, Falck-Ytter $Y$, Glasziou P, DeBeer H, Jaeschke R, Rind $D$, Meerpohl J, Dahm P, Schünemann HJ. GRADE guidelines: 1. IntroductionGRADE evidence profiles and summary of findings tables. J Clin Epidemiol 2011;
64:383-394.

16. Guo B, Moga C, Harstall C, Schopflocher D. A principal component analysis is conducted for a case series quality appraisal checklist. J Clin Epidemiol 2016; 69:199-207.

17. Gazis AN, Beuing O, Franke J, Jollenbeck B, Skalej M. Bipolar radiofrequency ablation of spinal tumors: Predictability, safety and outcome. Spine J 2014; 14:604-608.

18. Georgy BA. Bone cement deposition patterns with plasma-mediated radiofrequency ablation and cement augmentation for advanced metastatic spine lesions. AJNR Am J Neuroradio 2009; 30:1197-1202.

19. Gevargez A, Groenemeyer DH. Imageguided radiofrequency ablation (RFA) of spinal tumors. Eur J Radiol 2008; 65:246-252.

20. Nakatsuka A, Yamakado K, Takaki H, Uraki J, Makita M, Oshima F, Takeda K. Percutaneous radiofrequency ablation of painful spinal tumors adjacent to the spinal cord with real-time monitoring of spinal canal temperature: A prospective study. Cardiovasc Intervent Radiol 2009; 32:70-75.

21. Wallace AN, Greenwood TJ, Jennings JW. Radiofrequency ablation and vertebral augmentation for palliation of painful spinal metastases. J Neurooncol 2015; 124:111-118.

22. Dabravolski D, Lahm A, Kasch R, Merk $\mathrm{H}$. Minimally invasive treatment of tumours and metastases in the spine by plasma field therapy (cavity coblation) and vertebro-/kyphoplasty with and without additional dorsal percutaneous instrumentation. Z Orthop Unfall 2014; 152:489-497.

23. Georgy BA, Wong W. Plasma-mediated radiofrequency ablation assisted percutaneous cement injection for treating advanced malignant vertebral compression fractures. AJNR Am J Neuroradiol 2007; 28:700-705.

24. Hillen TJ, Anchala P, Friedman MV, Jennings JW. Treatment of metastatic posterior vertebral body osseous tumors by using a targeted bipolar radiofrequency ablation device: Technical note. Radiology 2014; 273:261-267.

25. Greenwood TJ, Wallace A, Friedman MV, Hillen TJ, Robinson CG, Jennings
JW. Combined ablation and radiation therapy of spinal metastases: A novel multimodality treatment approach. Pain Physician 2015; 18:573-581.

26. Wallace AN, Tomasian A, Vaswani D, Vyhmeister R, Chang RO, Jennings JW. Radiographic local control of spinal metastases with percutaneous radiofrequency ablation and vertebral augmentation. AJNR Am J Neuroradiol 2016; 37:759-765.

27. Kurup AN, Callstrom MR. Image-guided ablation of skeletal metastases. In: Drews RE, Abrahm J, Savarese DM (eds). UpToDate. UpToDate Inc., Waltham, MA. www.uptodate.com. Date Accessed 10/01/2017.

28. Filippiadis D, Tutton S, Mazioti A, Kelekis A. Percutaneous image-guided ablation of bone and soft tissue tumours: A review of available techniques and protective measures. Insights Imaging 2014; 5:339-346.

29. Kurup AN, Schmit GD, Morris JM, Atwell TD, Schmitz JJ, Weisbrod AJ, Woodrum DA, Eiken PW, Callstrom MR. Avoiding complications in bone and soft tissue ablation. Cardiovasc Intervent Radiol 2017; 40:166-176.

30. Tsoumakidou G, Too CW, Koch G, Caudrelier J, Cazzato RL, Garnon J, Gangi A. CIRSE guidelines on percutaneous vertebral augmentation. Cardiovasc Intervent Radiol 2017; 40:331-342.

31. Zhu JC, Yan TD, Morris DL. A systematic review of radiofrequency ablation for lung tumors. Ann Surg Oncol 2008; 15:1765-1774.

32. Iannuccilli JD, Dupuy DE, Mayo-Smith WW. Solid renal masses: Effectiveness and safety of image-guided percutaneous radiofrequency ablation. Abdom Imaging 2012; 37:647-658.

33. Zheng X, Bo ZY, Wan W, Wu YC, Wang TT, Wu J, Gao DJ, Hu B. Endoscopic radiofrequency ablation may be preferable in the management of malignant biliary obstruction: A systematic review and meta-analysis. J Dig Dis 2016; 17:716-724.

34. Munk PL, Murphy KJ, Gangi A, Liu DM. Fire and ice: Percutaneous ablative therapies and cement injection in management of metastatic disease of the spine. Semin Musculoskelet Radiol 2011; 15:125-134. 